$\underline{\text { Emotion and cognition processes in preschool children }}$

By: Esther M. Leerkes, Matthew Paradise, Marion O'Brien, Susan D. Calkins, and Garrett Lange

Leerkes, E. M., Paradise, M., Calkins, S., O’Brien, M., \& Lange, G. (2008). Emotion and cognition processes in preschool children. Merrill Palmer Quarterly, 54, 102-124.

Made available courtesy of Wayne State University Press:

https://www.wsupress.wayne.edu/journals/detail/merrill-palmer-quarterly

***(C) Wayne State University Press. Reprinted with permission. No further reproduction is authorized without written permission from Wayne State University Press. ***

\begin{abstract}
:
The core processes of emotion understanding, emotion control, cognitive understanding, and cognitive control and their association with early indicators of social and academic success were examined in a sample of 1413 -year-old children. Confirmatory factor analysis supported the hypothesized four-factor model of emotion and cognition in early childhood. A subsequent structural model indicated that emotion understanding processes were significantly positively associated with early indicators of academic success, while emotion control processes were inversely related to socioemotional problems. These results point to the utility of an integrated model of emotion and cognition in early development and offer support for the differentiation of understanding and control processes within these developmental arenas as a framework for future study.
\end{abstract}

Keywords: preschool | emotion processes | cognition processes

Article:

$* * *$ Note: Full text of article below 


\title{
Emotion and Cognition Processes in Preschool Children
}

Esther M. Leerkes, Matthew Paradise, Marion O'Brien, Susan D. Calkins, and Garrett Lange, University of North Carolina at Greensboro

\begin{abstract}
The core processes of emotion understanding, emotion control, cognitive understanding, and cognitive control and their association with early indicators of social and academic success were examined in a sample of 141 3-year-old children. Confirmatory factor analysis supported the hypothesized four-factor model of emotion and cognition in early childhood. A subsequent structural model indicated that emotion understanding processes were significantly positively associated with early indicators of academic success, while emotion control processes were inversely related to socioemotional problems. These results point to the utility of an integrated model of emotion and cognition in early development and offer support for the differentiation of understanding and control processes within these developmental arenas as a framework for future study.
\end{abstract}

In the study of early development, investigators have tended to focus on either emotional predictors of social processes or cognitive predictors of academic skills and have treated the developmental areas of emotion and cognition as largely separate from one another. Thus, links have been established between emotionality, emotion regulation, and emotion understand-

Esther M. Leerkes, Marion O'Brien, and Garrett Lange, Department of Human Development and Family Studies; Matthew Paradise and Susan D. Calkins, Department of Psychology.

This research was supported by a grant from the Office of the Provost (External Proposal Development Incentive Program) at the University of North Carolina at Greensboro. We thank the families who generously gave their time to participate in the study, Stuart Marcovitch for his helpful comments on a draft of this manuscript, and the UNCG Family Research Center staff and students: Cheryl Ann Sexton, Lauren Keel Shinn, J. Benjamin Hinnant, Jeff Gredlein, J. Matthew Skinner, Leigh Parrish, and Cheryl Sarratt.

Correspondence should be addressed to the first author at the Department of Human Development and Family Studies, The University of North Carolina at Greensboro, P.O. BOX 26170, Greensboro, NC, 27402-6170. Phone: (336) 256-0094. Fax: (336) 334-5076. E-mail: emleerke@uncg.edu.

Merrill-Palmer Quarterly, January 2008, Vol. 54, No. 1, pp. 102-124. Copyright ( 2008 by Wayne State University Press, Detroit, MI 48201. 
ing and early childhood social competence (e.g., Calkins \& Fox, 2002; Denham et al., 2003; Eisenberg et al., 1995, 1996). Similarly, research on early academic success has emphasized cognitive precursors, especially processes associated with metacognition (e.g., Bransford, Brown, \& Cocking, 1999; Gaskins, 1994), strategy use (e.g., Griffin, Case, \& Siegler, 1994; Pressley, 1995), and other skills central to executive functioning such as memory and problem solving (e.g., Stipek \& Ryan, 1997). To date, there has been little research addressing the contributions of emotional processes to academic performance or cognitive processes to social skills. Furthermore, the interconnections between emotion and cognition have not been thoroughly explored, despite recent acknowledgment that integration across these areas of development will likely yield a more complete understanding of early development and successful adaptation in home, peer, and school contexts (Bell \& Wolfe, 2004; Blair, 2002; Gray, 2004). The purpose of this study was to examine the associations among emotion understanding, emotion control, cognitive understanding, and cognitive control early in the preschool period to determine if these are unique or overlapping areas of development and to examine their relation to concurrent indices of social and academic skills.

Several lines of work suggest the potential utility of examining the relations between emotion and cognition processes in a single study. First, recent work in the area of self-regulation in both children and adults suggests that both emotion and cognitive processes are implicated in the successful regulation of thought and behavior (Baumeister \& Vohs, 2004; Gray, 2004; Lewis \& Stieben, 2004). A second literature that bears on this issue of emotion-cognition relations addresses early indices of psychological adjustment, focusing specifically on early childhood psychopathology. This work emphasizes that children who experience early adjustment difficulties, characterized either by acting-out externalizing problems or anxiety-based internalizing problems, often show deficits in both emotion and cognitive processing (Nigg \& Huang-Pollock, 2003). Finally, recent work in developmental neuroscience suggests that there are two separate but closely related and potentially reciprocal subdivisions within the anterior cingulate cortex, one governing cognitive and attentional processes and the other governing emotional processes (Davidson, Putnam, \& Larson, 2000; Davis, Bruce, \& Gunnar, 2002). The functional relation between these areas provides a biological mechanism for behavioral integration of emotional and cognitive processes in early childhood.

Thus, several productive areas of current research provide a rationale for examining the emergence of emotion-cognition relations in early development. Moreover, recent developmental work supports the hypothesis that 
these relations may be observable as early as the preschool period. For example, recent research suggests that the ability to control emotional arousal allows children to engage in challenging tasks that provide opportunities for using and practicing executive function skills (Calkins \& Dedmon, 2000). During the second and third years, children also acquire a voluntary attentional system that enables them to use deliberate and effortful attentional strategies (Walden \& Smith, 1997); these changes in the planful control of attention undoubtedly contribute to goal-directed behavior in both the emotional and cognitive spheres, skills that translate into successful social and academic outcomes.

An important first step in examining the relations between emotional and cognitive development involves specification of the component processes within each area of development (Blair, 2002; Gray, 2004). Drawing from previous literature, we propose that emotion and cognition processes can be separated into two components: control and understanding. Control processes refer to the regulation of affect in social and nonsocial contexts and the regulation of executive function in cognitive tasks. Understanding processes include the meta-cognitive and meta-emotion knowledge that young children begin to internalize during the preschool period. This approach to analyzing emotion and cognition processes builds upon previously described approaches in both areas. For example, Saarni's (1990) model of emotional competence and Halberstadt, Denham, and Dunsmore's (2001) model of affective social competence both implicate elements of emotion understanding (e.g., awareness and identification of one's own and others' emotions) and emotional control (e.g., the ability to cope by using self-regulatory strategies, management, and regulation of affect) as essential to early adaptive development. In these models, the underlying emotional processes are presented as distinct but interrelated skills. Likewise, in the cognitive domain, knowledge, metacognition, and strategy employment are all believed to influence performance on academic and cognitive tasks (Pressley, 1995), and theory of mind (an element of cognitive understanding) and executive function have been viewed as interrelated but distinct dimensions of cognitive development (Perner, Lang, \& Kloo, 2002). Our approach is unique in that we identify multiple skills that appear similar in function-either understanding or controlacross the emotion and cognition arenas. Although we acknowledge that other emotion and cognition processes are displayed by young children (e.g., empathy, attributions, planning, attentional control), we have focused on a set of specific processes that have been linked consistently to social and academic performance in young children in prior research (Eisenberg et al., 1995, 1996; Stipek \& Ryan, 1997). 
The four factors of interest are described below along with an overview of how they relate to the outcomes of interest. Emotional control processes are generally referred to as emotional reactivity and emotional regulation; these involve responses produced or inhibited during an affectively arousing situation (Buss \& Goldsmith, 1998; Kopp, 1989). Emotional control helps children maintain or modulate their arousal, facilitating positive social interaction and effective problem solving (Eisenberg et al., 1995, 1996). Emotion understanding includes the ability to recognize and label one's own and others' emotions, tie them to situations, understand their causes, identify familial and cultural display rules, and recognize disparity between emotional displays and felt emotions (Campos \& Barrett, 1984; Denham, 1998). Knowledge about emotions allows children to communicate their own emotional experiences effectively and respond appropriately to the emotional signals of other people, thereby enhancing social competence (Denham et al., 2003). Cognitive control processes include the set of skills often referred to as executive function, particularly inhibitory control and working memory (Carlson, Moses, \& Claxton, 2004). These abilities appear to develop somewhat interdependently (Bjorklund \& Harnishfeger, 1995) and enhance children's ability to engage in effective goal-directed behavior by reducing their attention to nonessential stimuli and allowing them to consider multiple solutions to a problem. Executive function skills have been linked to literacy and mathematical reasoning in young children (Espy, McDiarmid, Cwik, Stalets, Hamby, \& Senn, 2004; Gathercole, Brown, \& Pickering, 2003). Cognitive understanding involves children's understanding of their own and others' mental states and is typically referred to as theory of mind (Flavell, Miller, \& Miller, 2002). Mental state understanding and the ability to view situations from multiple perspectives enable children to communicate more effectively with others and may indicate metacognitive maturity more generally (Astington, 2003; TagerFlusberg \& Sullivan, 2000).

The empirical literature on emerging relations across these four factors is neither large nor systematic. For example, there is little research examining the extent to which either negative emotionality or emotion regulation are linked to the display and development of early cognitive skills or the extent to which executive function skills may account for individual differences in children's ability to regulate problem solving in the social domain. Concurrent relations have been found between cognitive functioning and emotion knowledge (Denham, Zoller, \& Couchoud, 1994; Walden \& Field, 1990), and preschoolers' attentional control and behavioral control (a construct much like emotional control) predict emotion knowledge in first grade (Schultz, Izard, Ackerman, \& Youngstrom, 2001). To date, the role 
that emotion understanding may play in the acquisition of cognitive understanding and control has not been examined. Likewise, measures of false belief understanding, a component of Theory of Mind, correlate with social skills (Tager-Flusberg \& Sullivan, 2000; Watson, Nixon, Wilson, \& Capage, 1999) and with executive function (Carlson \& Moses, 2001); however, the mechanisms linking mental state understanding, emotion understanding, and the control processes within the cognitive and emotional arenas have yet to be explored. Examining the associations among each of the identified components may be useful in relation to theory and research because there is little behavioral data demonstrating emotion-cognition links in the this age group despite a burgeoning of data suggesting links at the neural level. Furthermore, identifying cross-area (emotion-cognition) or cross-component (control-understanding) associations may be useful in the design and delivery of early interventions intended to enhance cognitive or emotional development.

Although recent theoretical work clearly suggests that these emotioncognition processes influence, and perhaps support, one another during the preschool years (Blair, 2002; Nigg \& Huang-Pollock, 2003) and there is considerable support for emotion-cognition interactions at the neural level (Davidson, Pizzagalli, Nitschke, \& Kalin, 2003), there has yet to be a comprehensive empirical investigation of the relations among these specific emotion and cognitive processes. In the current project, we examined selected dimensions of emotion control, emotion understanding, cognitive control, and cognitive understanding in young preschoolers in order to describe the extent of association between these four processes.

Based on evidence that emotion-cognition linkages exist at the neural level (Davidson et al., 2000; Davis et al., 2002) but tempered by the empirical literature demonstrating later emerging skills in some developmental areas (e.g., cognitive control develops later than emotion control and understanding; Blair, 2002; Posner \& Rothbart, 2000), we hypothesize that control and understanding in the emotion and cognition arenas are interrelated but discrete factors during the early preschool years (Figure 1, Model A). We compare this four-factor model to two alternative two-factor models. In the first, emotion processes and cognition processes are viewed as separate aspects of early development because emotion and cognition have typically been examined separately in the developmental literature (see Figure 1, Model B). In the other comparison model, control and understanding are separate components given that they reflect different types of processes that may be related across emotion and cognition areas of development (e.g., emotion and cognitive understanding both include elements of perspective taking, and emotion and cognitive control both include inhi- 


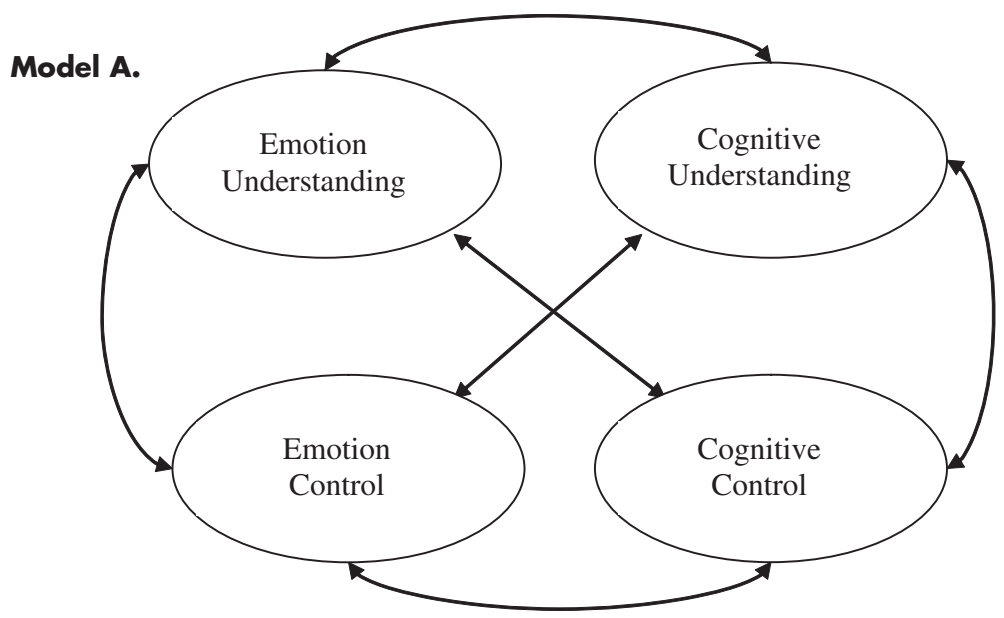

Model B.

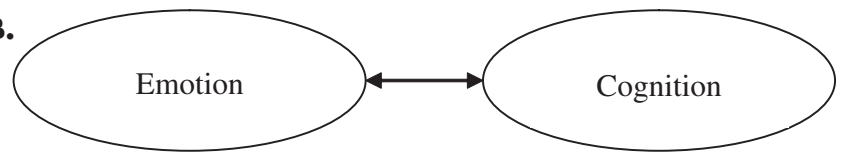

Model C.

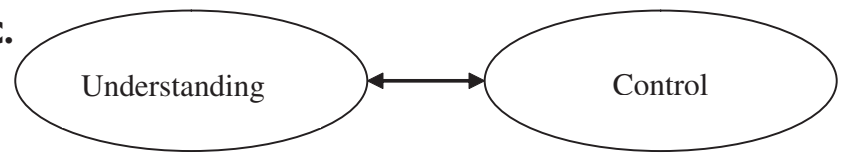

Figure 1. Model A, Proposed four-factor model. Model B, Alternative model 1: Two-factor emotion/cognition model. Model C, Alternative model 2: Two-factor understanding/control model.

bition of prepotent responses; see Figure 1, Model C). Confirmatory factor analysis procedures offer a direct statistical test of the competing two- and four-factor models of these constructs.

Extensions of these models allow us to examine the relations between each of the four constructs and measures of early social and academic competence. Scant research has explored the combined contributions of emotional and cognitive processes to the development of the social and academic skills necessary for school success, despite recent acknowledgment that such integration will likely yield the most complete understanding of early adjustment (Bell \& Wolfe, 2004; Blair, 2002; Gray, 2004). Thus, a significant and unique contribution of the current project is that all four factors are examined in the same group of children simultaneously so 
that their independent relations with early indicators of success can be assessed. Based on theory and prior research, we propose that emotion understanding and emotion control are more strongly linked to measures of early social and academic success than either of the cognitive factors. Our rationale for this hypothesis is derived from recent work in the areas of emotion regulation and self-regulation more broadly construed. First, emotion understanding and emotion control processes appear to emerge earlier in development than do cognitive control processes (Blair, 2002). To the extent that emotion factors are better developed at this early point in development, it is likely that they are more tightly linked with early social and academic performance. Second, it is clear that emotions have the capacity to organize and facilitate, or disorganize and disrupt, other psychological processes (Cole, Martin, \& Dennis, 2004). To the extent that children understand and control emotions successfully, they have a greater opportunity to attend to, assimilate, and process events in the world around them, thus enhancing both social and academic competence. Finally, beyond these in-the-moment effects of emotion, there is emerging empirical evidence that early affective experience influences the acquisition of cognitive control skills of attention and working memory (Bell \& Wolfe, 2004).

In sum, the primary goals of the study were (a) to determine the extent to which processes of control and understanding can be differentiated within the emotional and cognitive areas, (b) to delineate the relations among the four factors in the early preschool period, and (c) to examine the relation between each of the four factors and standard measures of children's social and academic competence. We focus our investigation on 3.5year-old children because this is the earliest age at which we could reliably assess each of the constructs of interest.

\section{Method}

\section{Participants}

Participants were 141 preschool children who averaged 3.5 years old at the time of the first assessment; $51 \%$ were male. The sample mirrored the diversity of the surrounding community: two-thirds of the participants were white, one-fourth were African American, and one-tenth were biracial or other. The sample was likewise economically and educationally heterogeneous. The middle $50 \%$ of the sample came from families with annual incomes between $\$ 24,000$ and $\$ 72,000$, whereas $16 \%$ of families reported annual incomes less than $\$ 18,000$. Forty percent of the mothers had graduated from college, while $15 \%$ had no postsecondary education. Seventy percent of the children were living in two-parent families; the rest lived in single-parent homes. 
Procedures and Measures

Participating families were recruited from preschools and child care centers in a small city in the southeastern United States through letters sent home with the children. Families interested in participating returned contact information to the researchers, who then called the families to schedule data-collection visits. Two laboratory-based assessments were scheduled for each participant within plus or minus 2 months of the child's 3.5-year birthday. Each assessment lasted approximately 1.5 hours. Children were videotaped while completing tasks assessing emotional and cognitive control and understanding as well as standardized measures of achievement. Because individual differences across the group of children were our primary interest, task order was held constant. Mothers provided written consent and completed questionnaires during the lab session.

\section{Emotion Understanding}

Labeling of emotions. Following the procedure used by Denham (1986), children were presented four felt faces depicting the emotions happy, sad, angry, and scared and were asked to name each expression (e.g., "How is this person feeling right now?") to assess accuracy of verbal emotion labeling. Children were also asked to point to each expression when requested to assess accuracy of nonverbal emotion recognition. For each emotion, children received a score of 2 if they identified the correct emotion, 1 if they identified an incorrect emotion of the correct valence (e.g., sad for angry), and 0 if they identified an emotion of the incorrect valence (e.g., happy for sad). Recognition and labeling scores correlated $(r$ [137] $=$ $.38 ; p<.001)$ and were summed to yield one measure of labeling of emotions with a possible range from 0 to 16 .

Affective perspective taking. The vignettes of emotion-eliciting situations developed by Denham (1986) were used to assess children's understanding of others' emotions. Vignettes were presented as puppet tasks. The children were asked to indicate how the puppet felt by affixing a felt face depicting happiness, sadness, anger, or fear to the puppet. The first 4 vignettes involved situations that evoke nonequivocal emotional reactions (e.g., happiness at getting an ice cream cone). The remaining 13 vignettes were more equivocal situations when the protagonist puppet portrayed an emotional response that the mother reported as atypical for her child at the beginning of the session. For example, if a mother indicated that her child would feel scared about being approached by a large, friendly dog, the puppet enacted happiness using standard verbal and visual cues. For each vignette, children received a 0,1 , or 2 for the face they selected using the 
same criteria as the emotion labeling scoring described above. Separate scores were calculated for nonequivocal (possible range 0 to 8 ) and equivocal affective perspective taking (possible range 0 to 26) by summing scores across the vignettes. The two measures correlated $(r[137]=.55 ; p<.001)$ and were summed to yield one index of affective perspective taking.

Knowledge of emotion causes. Children's ability to explain the reasons for experiencing emotions was examined using a puppet task developed by Denham, Zoller, and Couchoud (1994). One of the four emotion faces was placed on a puppet, and children were asked to identify the emotion. Then the examiner asked, "What made the puppet feel this way?" (If the child identified an incorrect emotion, the examiner first provided the label for the correct emotion.) Children were encouraged to report as many as four possible reasons, and their responses were recorded verbatim and coded for the number of accurate, independent causes given (possible range 0 to 4 ) for each of the four emotions. Accuracy was defined using criteria established in past research such as correct causes of anger involve goal blockage (Barrett \& Campos, 1987; Stein \& Jewett, 1986). The interobserver agreement on the codes was $84.5 \%$. The number of correct explanations was summed across all four emotions to yield a total score for knowledge of emotion causes that could range from 0 to 16 .

\section{Cognitive Understanding}

Appearance-reality distinction. This task, developed by Flavell, Flavell, and Green (1983), assessed whether children could accurately describe differences between an object's real nature and its apparent nature when its properties were modified. To do so correctly, children must understand that their current perception of the object, a mental state, is inaccurate. The child was shown two realistic-looking imitation objects: a candle in the shape of an apple and an egg made of wood. Then, the color was modified by placing a sheet of blue tinted plastic in front of each of the objects, and the size was modified by using a large magnifying lens. The child was asked a series of questions about what the object looked like while modified (e.g., "Does it look blue or red?" or "Does it look big, or does it look little?") and what the properties of the object really were (e.g., "Is it really, really blue, or is it really, really red?"). Children received a score of 1 for each correct answer for each of these questions. Appearance reality color and size scores were calculated by summing the number of correct answers to questions about color and size across the apple and egg trials, yielding two scores that could range from 0 to 4 . 
Unexpected contents. This task, developed by Astington and Gopnik (1988), assessed the children's false belief reasoning by asking them to identify their own and another character's belief about the contents of two containers. Each child was shown a crayon box that contained adhesive bandages and a Play-Doh canister that contained stickers. First, the examiner presented the box and asked the child, "What do you think is in here?" The examiner then revealed the actual contents and asked, "Before we opened this, what did you think was in here?" Then, an Elmo puppet was introduced, and the examiner asked the child what Elmo, who had not seen the actual contents of the box, would think was inside. Children earned a score of 1 for each correct answer summed across both trials (i.e., possible scores ranged from 0 to 4 ).

\section{Emotional Control}

Children's Behavior Questionnaire. The Children's Behavior Questionnaire (CBQ-Short), developed by Putnam and Rothbart (2003), assesses temperament in 3 to 7 year olds. Mothers described their child's typical reactions to various situations with a 7-point Likert scale ranging from 1 (extremely untrue) to 7 (extremely true). Of interest in the present analyses was the 6-item falling reactivity/soothability subscale (e.g., "is easy to soothe when upset"). Scale items were averaged to yield a measure of soothability (6 items, $\alpha=.74$ ).

Emotion Regulation Checklist. Parents completed the Emotion Regulation Checklist (Shields \& Cicchetti, 1998), a 24-item questionnaire, by rating how frequently their child engaged in certain behaviors on a scale from 1 (never) to 4 (always). The checklist includes two subscales: lability/ negativity (10 items, $\alpha=.77$; e.g., "is easily frustrated") and emotion regulation (14 items, $\alpha=.68$; e.g., "can modulate excitement in emotionally arousing contexts"). Items were summed within each subscale.

\section{Cognitive Control}

Kaufman Assessment Battery for Children. The number recall subtest of the Kaufman Assessment Battery for Children (K-ABC), developed by Kaufman and Kaufman (1983), was administered to children to assess working memory capacity. The examiner recited a series of numbers, and the child was asked to repeat them in the same sequence. The score is the number of digits in the largest sequence completed accurately by the child. Forward digit span is a measure of working memory to the extent that children 
must actively maintain storage of end-string numerals (via attentional or rehearsal control) while at the same time verbally producing earlierappearing numerals.

Children's Stroop Test. The Children's Stroop Test (CST) was developed by Gerstadt, Hong, and Diamond (1994) from the classic Stroop task (Stroop, 1935), a widely used index of impulsivity and inhibitory control. Children were presented with cards, half of which were black with a yellow moon and stars and the other half of which were white with a bright sun, and were instructed to say "day" in response to the black cards and "night" to the white cards. Following two practice trials, each card type was presented 7 times in fixed order. The child's score is the number of correct responses to the 14 test trials.

\section{Outcomes: Early Academic and Socioemotional Functioning}

Woodcock-Johnson Standard Battery. The Woodcock-Johnson Standard Battery (WJ III), developed by Woodcock, McGrew, and Mather (2001), is a comprehensive standardized measure of cognitive and academic abilities. For the present study, the letter-word identification subtest that assesses the ability to identify individual letters and words and the applied problems subtest that assesses the ability to solve practical math problems were scored. These scales were selected because they reflect emerging skills relevant to subsequent academic success. Raw scores are used in data analysis.

\section{Socioemotional Problems}

Child Behavior Checklist. The Child Behavior Checklist (CBCL 1.5-5), developed by Achenbach and Rescorla (2000), is a 99-item questionnaire that indexes children's behavioral and emotional problems and includes 2 broadband problem scales (internalizing, externalizing). The internalizing and externalizing scores correlated significantly $(r[137]=.39$, $p<.001$ ), so the raw total problems score was used in this study to index socioemotional problems.

\section{Results}

\section{Descriptive Data}

Descriptive statistics for each of the measures included in the model are shown in Table 1, and zero-order correlations among the measures are shown in Table 2. 
Table 1. Descriptive Statistics

\begin{tabular}{lrrrrrr}
\hline & $\mathrm{N}$ & Mean & SD & Range & Skew & Kurtosis \\
\hline $\begin{array}{l}\text { Processes } \\
\text { Emotional understanding }\end{array}$ & & & & & & \\
Labeling of emotions & 139 & 12.09 & 3.02 & $0-16$ & -1.36 & 2.15 \\
Affective perspective taking & 139 & 21.38 & 6.27 & $0-33$ & -.93 & 1.08 \\
Knowledge of emotion causes & 134 & 5.02 & 3.40 & $0-13$ & .31 & .71 \\
Cognitive understanding & & & & & & \\
Appearance/reality color & 140 & 2.07 & 1.00 & $0-4$ & .01 & .04 \\
Appearance/reality size & 140 & 2.20 & .82 & $0-4$ & .12 & 1.06 \\
Unexpected contents & 141 & .91 & 1.18 & $0-4$ & .21 & .60 \\
Emotional control & & & & & & \\
CBQ soothability & 131 & 5.01 & .84 & $1.7-6.7$ & -.80 & 1.74 \\
ERC lability/negativity & 140 & 12.17 & 4.68 & $2-31$ & .57 & 1.40 \\
ERC emotion regulation & 140 & 18.84 & 2.89 & $6-24$ & -.83 & 2.3 \\
Cognitive control & & & & & & \\
K-ABC digit span & 136 & 4.85 & 2.45 & $0-11$ & -.06 & .05 \\
Children's Stroop Test & 135 & 6.66 & 4.69 & $0-14$ & -.18 & -1.23 \\
Outcomes & & & & & &
\end{tabular}

\section{Outcomes}

Early academic success

$\begin{array}{lllllll}\text { WJ Letter-word identification } & 141 & 4.75 & 3.33 & 0-14 & .84 & -.40 \\ \text { WJ Applied problems } & 141 & 8.79 & 3.92 & 0-19 & -.32 & -.04\end{array}$

Socioemotional problems

$\mathrm{CBCL}$ total score

$\begin{array}{llllll}139 & 35.67 & 15.28 & 4-88 & .56 & .68\end{array}$

\section{Tests of Model Fit}

The relations across the measures of emotion and cognitive processes were assessed via structural equation modeling (SEM) using the AMOS module of the SPSS software package. In this framework, an underlying measurement model of the four proposed constructs (four discrete factors) was compared with alternative formulations using confirmatory factor analytic (CFA) techniques. Specifically, a model postulating the four discrete factors (emotion understanding, cognitive understanding, emotion control, and cognitive control) was compared with each of the simpler two-factor models that included either emotion and cognition or control and under- 
Emotion and Cognition in Preschool

Table 3. Comparison across Models

\begin{tabular}{lccccccc}
\hline Model & $\chi^{2}$ & Df & $p$ & $\Delta \chi^{2}$ & CFI & IFI & RMSEA \\
\hline Four factors & 41.39 & 38 & .33 & & .978 & .982 & .025 \\
Emotion and cognition & 84.38 & 40 & .00 & $42.99^{*}$ & .716 & .757 & .089 \\
Understanding and control & 60.01 & 40 & .03 & $18.62^{*}$ & .872 & .890 & .060 \\
\hline${ }^{*} p<.01$. & & & & & & &
\end{tabular}

standing. Using Kline's (1998) strategy for assessing the relative strength of competing models, the fit of each of the two-factor models (emotion/ cognition and understanding/control) was assessed first, followed by the hierarchically more complex four-factor model postulated above. In this class of multifactor models, fixing specific correlations between factors to be equal to 1 allows for direct statistical comparisons between models using a difference in chi-square test as well as affording relevant fit indices to assess relative model strength. Here, we would expect that the more complex four-factor model would show a statistically significant improvement (i.e., reduction) in chi-square and measures of model fit when compared to the simpler models.

The confirmatory analyses comparing the four-factor model with the two-factor models are summarized in Table 3. The four-factor solution offers a significantly better fit to the data than either the two-factor emotion/cognition or understanding/control models as demonstrated by the significantly smaller chi-square value. These results indicate that, for our sample, the four proposed factors are related but discrete constructs. The fit of the model to the data was good, as noted by CFI and IFI values greater than .90 and RMSEA value less than $.06(90 \% \mathrm{CI}=.00, .06)$.

The resulting measurement model (Figure 2) shows that the correlations between cognitive and emotional understanding and between cognitive and emotional control were significant. Emotional understanding was associated with each of the other three factors, particularly with cognitive control. In contrast, cognitive understanding was not significantly related to either emotional or cognitive control.

\section{Relations of Model Domains to Academic and Socioemotional Functioning}

A second structural model was used to assess the relation of each of the four factors to indicators of early academic performance and socioemotional problems (Figure 3). Emotional understanding was significantly related to 


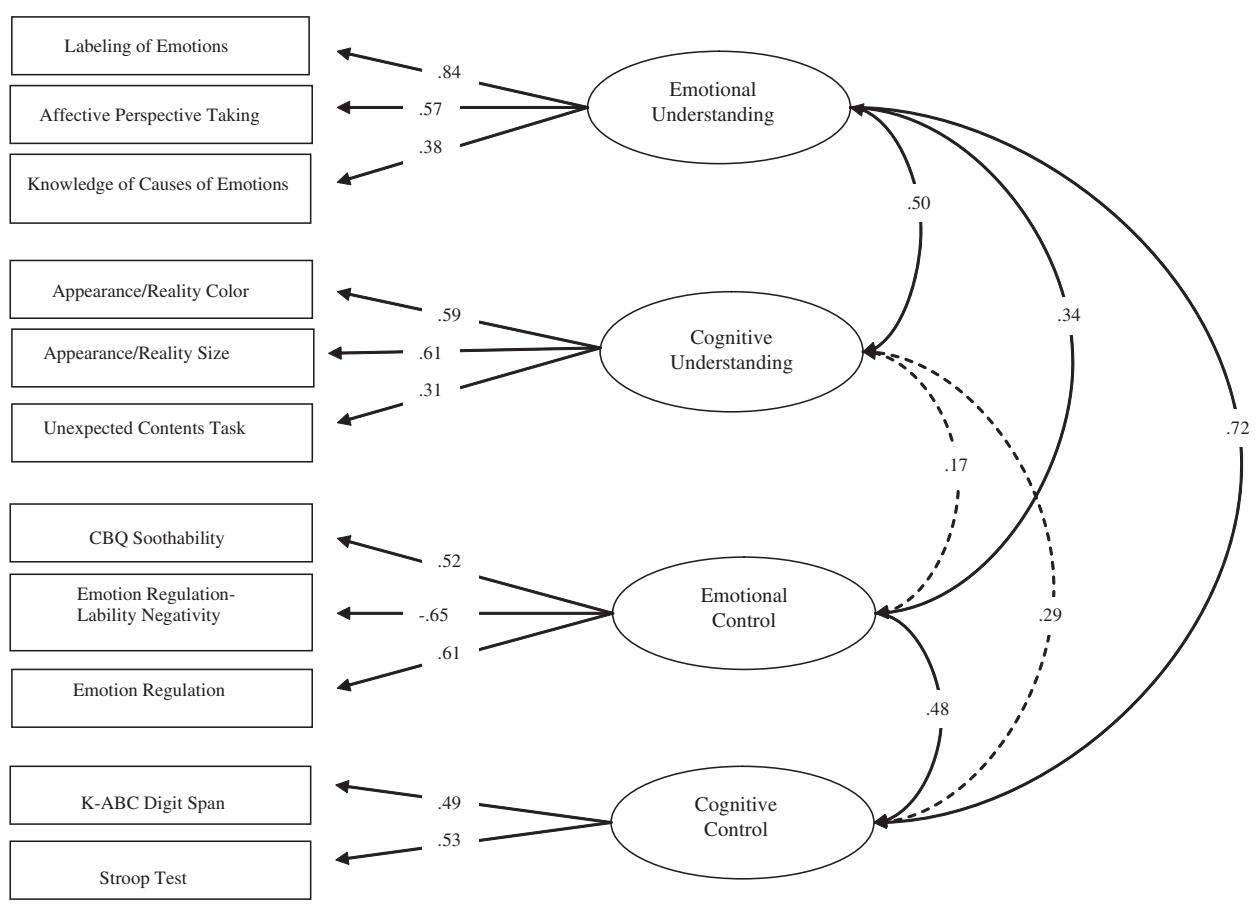

Figure 2. Four-factor model of cognition and emotion. Dashed lines indicate nonsignificant paths; solid lines indicate paths significant at $p<.05$.

academic performance and emotional control to the absence of socioemotional problems. Neither cognitive understanding nor cognitive control was associated with the measures of academic and social functioning. The fit of the model was $\operatorname{good}\left(\chi^{2}=70.47, \mathrm{df}=64, p=.270, \mathrm{CFI}=.98, \mathrm{RMSEA}=.027\right.$ $[90 \% \mathrm{CI}=.000, .059])$.

\section{Discussion}

Our study offers clear empirical support for a four-factor model of emotion and cognition processes in preschool, and this model further identifies quantifiably discrete constructs that include emotional understanding, cognitive understanding, emotional control, and cognitive control. Although the four-factor model was the best-fitting model in this sample of 3.5 year olds, there were moderate associations between understanding processes and control processes across emotion and cognition. This result requires further research and replication but may suggest underlying neural bases for the developmental processes of control and understanding that are then applied to different aspects of experience. In contrast, there was least sup- 
Emotion and Cognition in Preschool

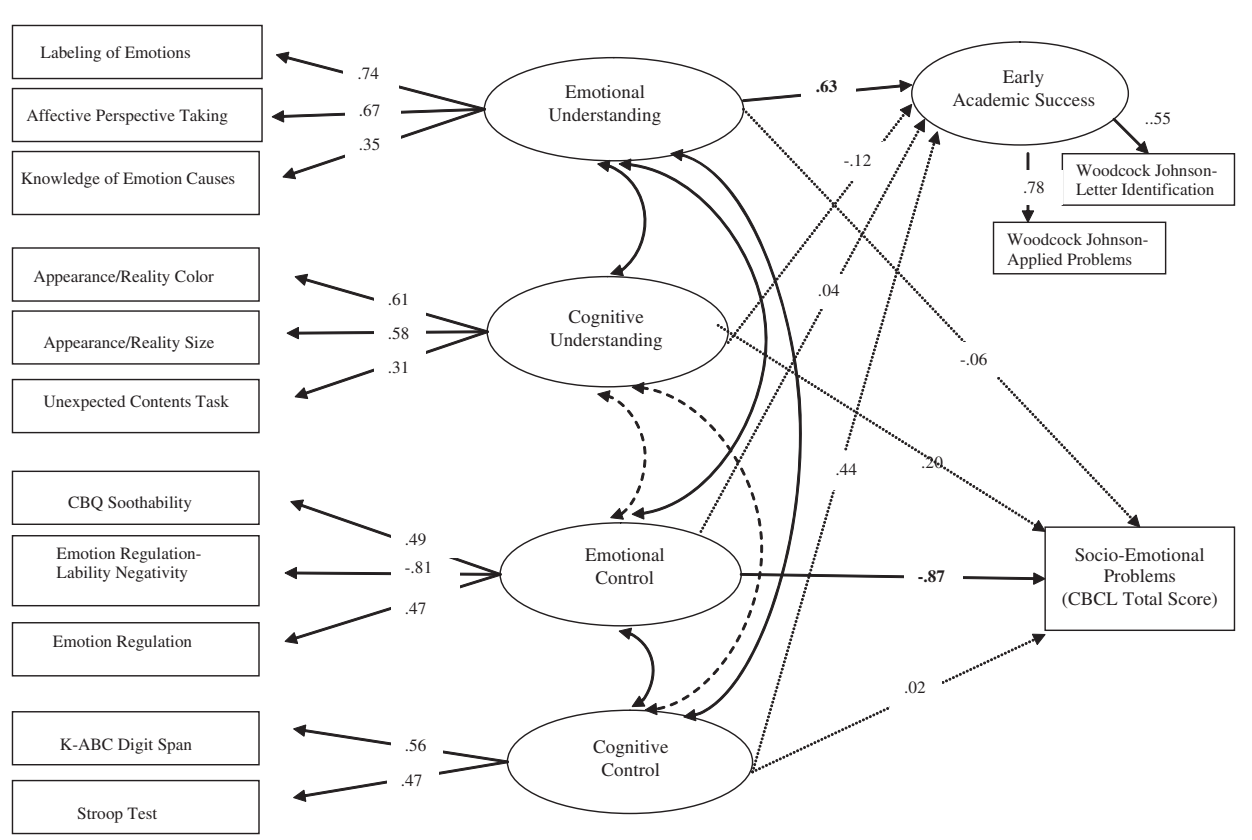

Figure 3. Structural model predicting early academic success and socioemotional problems. Dashed lines indicate nonsignificant paths; solid lines indicate paths significant at $p$ $<.05$.

port for the competing two-factor emotion/cognition model, further indicating the importance of analyzing development across rather than within developmental areas. Important questions about the structure of and relationships among these components remain. Of particular interest are longitudinal questions examining stability or change in the four-factor structure and the extent to which skills in one area (e.g., emotion control) predict the development of skills in other domains (e.g., cognitive control) over time.

Consistent with the hypotheses, emotional control and understanding were more strongly linked to indicators of early social and academic competence than were cognitive processes. That emotional control is significantly and negatively related to behavior problems is consistent with the view that the ability to exercise control over the expression of emotion may have particular importance for the development of appropriate and adaptive social behavior during the preschool years. A limitation of the current analysis is that the measures of emotional control and behavior problems were collected by maternal report and therefore are subject to inflation by shared method variance. Nevertheless, this finding is consistent with the considerable literature in this area (e.g., Calkins \& Fox, 2002; Denham et al., 2003; Eisenberg et al., 1995, 1996), thereby supporting the 
view that emotional undercontrol is an early and robust predictor of socioemotional problems for preschool-aged children. Further research using observational and physiological indicators of these constructs is needed to confirm these associations.

That our emotion understanding factor was correlated with early academic skills offers support for our hypothesis about the primacy of emotion in early development given that it was evaluated simultaneously with cognitive control and understanding, constructs that have been more closely linked to academic functioning in prior literature. The indices of cognitive control were correlated significantly with performance on the WJ III as zero-order associations but not in the complete model when emotion understanding was included. This result demonstrates the importance of evaluating emotional and cognitive processes simultaneously. The capacity for recognizing emotional states in oneself and others as well as understanding the causes of emotion states may be one index of children's developing knowledge base that is reflected directly, above and beyond developing cognitive skills, in early academic functioning. This finding bolsters the recent recommendation that indices of emotional competencies be included in screens for school readiness (Denham, 2006).

Cognitive understanding was unrelated to early academic success both in the zero-order correlations and the full model. It may be that these skills are just emerging at this age. Children's performance on the appearancereality and unexpected contents tasks was variable; some of the children did not seem to understand the tasks and did not respond consistently. Likewise, associations between cognitive control and academic success may have been stronger if other control processes such as attentional control had been considered. Alternatively, there may be a lag between the development of cognitive control skills and their impact on behavior in academic and social contexts consistent with Riggs, Blair, and Greenberg's (2003) finding that executive function was unrelated to concurrent measures of behavior problems but predicted behavior problems two years later in elementary children. Finally, the WJ III scales are fairly straightforward and do not demand advanced cognitive skills (e.g., perspective taking) and therefore may not be sensitive to children's varying levels of understanding of perception or mental states. That the academic tasks were administered in the laboratory with little distraction, in contrast to a classroom environment with multiple distractions, may also have reduced the need for children to rely on cognitive control skills to perform well.

The primary contribution of this study is its focus on the joint contribution of emotion and cognitive processes to early childhood development. Our final structural model simultaneously estimates the relation between each of 
four discrete subdomains of emotion understanding, cognitive understanding, emotional control, and cognitive control and relevant indicators of early academic and social functioning. While such models necessarily simplify such complex constructs as emotion and cognition and while our academic and social measures were administered concurrently and therefore do not represent developmental outcomes, the study is one of the first attempts to empirically address the interconnection of emotional and cognitive processes in early childhood. The growing theoretical consensus that emotion and cognition are fundamentally linked across development has received limited empirical support to date. Thus, this study is an important first step in understanding what is almost certainly a dynamic and interactive process. Indeed, the natural extension of this work would focus on the dynamic, longitudinal association between emotional and cognitive development with specific attention to their reciprocal transactions over time. This study makes clear, however, that the differentiation of emotion and cognition processes into related subareas of control and understanding provides a useful framework for future study and that early emotional development, in particular, may be essential to the development of the competencies needed for social and academic functioning prior to school entry.

Three limitations of this work must be noted. First, the data are crosssectional and consequently do not describe the actual developmental processes at work. We are not able to draw causal conclusions about the role of these emotion and cognition processes in the development of one another or of early academic and social skills. Second, the use of maternal report for the measurement of emotion control and social adjustment is likely to inflate their association by virtue of shared method variance. Third, the cognitive control tasks administered may have been too difficult for some of the children; use of some other newly identified measures for young preschoolers (e.g., Hughes \& Esnor, 2005) may have altered the pattern of associations.

Despite these limitations, the findings from this study provide clear directions for future research. We have identified four domains of skills that we propose are important components of children's functioning during the preschool years. The logical next step in this program of research is to examine the trajectories of these domains across time to determine whether and how these processes relate to one another during the course of early development. Although recent theoretical work clearly suggests that the behavioral components of these emotion-cognition processes likely build on one another during the preschool years (Blair, 2002; Nigg \& Huang-Pollock, 2003), there is also considerable support for interaction between emotion and cognition at the neural level (Davidson et al., 2003). It is clearly time for a comprehensive 
investigation of the development and interrelation of these emotion and cognition processes across the preschool period. A second and important direction for future work lies in the examination of the biological bases of these emotion-cognition relations. Such efforts would provide important information with respect to the biological foundations of individual developmental trajectories. Furthermore, empirical data on the emergence of relations between the emotional and cognitive domains would contribute to a growing understanding of their interconnections emerging from physiological and neural data from adult populations. Finally, the role of the transition to school itself and its potential influence on the integration and differentiation of emotion and cognition offer rich ground for future study.

\section{References}

Achenbach, T. M., \& Rescorla, L. A. (2000). Manual for the ASEBA Preschool Forms and Profiles. Burlington: University of Vermont, Department of Psychiatry.

Astington, J. W. (2003). Sometimes necessary, never sufficient: False-belief understanding and social competence. In B. Repacholi \& V. Slaughter (Eds.), Individual differences in theory of mind: Implications for typical and atypical development (pp. 13-39). New York: Psychology Press.

Astington, J. W., \& Gopnik, A. (1988). Knowing you've changed your mind: Children's understanding of representational change. In J. W. Astington \& P. L. Harris (Eds.), Developing theories of mind (pp. 193-206). New York: Cambridge University Press.

Barrett, K. C., \& Campos, J. J. (1987). Perspectives on emotional development II: A functionalist approach to emotions. In J. D. Osofsky (Ed.), Handbook of infant development (2nd ed., pp. 555-578). New York: Wiley.

Baumeister, R. F., \& Vohs, K. D. (Eds.). (2004). Handbook of self-regulation: Research, theory, and applications. New York: Guilford.

Bell, M. A., \& Wolfe, C. D. (2004). Emotion and cognition: An intricately bound developmental process. Child Development, 75, 366-370.

Bjorklund, D. F., \& Harnishfeger, K. K. (1995). The role of inhibition mechanisms in the evolution of human cognition. In F. Dempster \& C. Brainerd (Eds.), New perspectives on interference and inhibition in cognition. New York: Academic Press.

Blair, C. (2002). School readiness: Integrating cognition and emotion in a neurobiological conceptualization of children's functioning at school entry. American Psychologist, 57, 111-127.

Bransford, J. D., Brown, A. L., \& Cocking, R. R. (Eds.). (1999). How people learn: Brain, mind, experience, and school. Washington, DC: National Academic Press. 
Buss, K. A., \& Goldsmith, H. H. (1998). Fear and anger regulation in infancy: Effects on the temporal dynamics of affective expression. Child Development, 69, 359-374.

Calkins, S. D., \& Dedmon, S. A. (2000). Physiological and behavioral regulation in two-year-old children with aggressive/destructive behavior problems. Journal of Abnormal Child Psychology, 2, 103-118.

Calkins, S. D., \& Fox, N. A. (2002). Self-regulatory processes in early personality development: A multilevel approach to the study of childhood social withdrawal and aggression. Development \& Psychopathology, 14, 477-498.

Campos, J., \& Barrett, K. (1984). Toward a new understanding of emotions and their development. In C. Izard, J. Kagan, \& R. Zajonc (Eds.), Emotions, cognition, and behavior (pp. 229-263). New York: Cambridge University Press.

Carlson, S. M., \& Moses, L. J. (2001). Individual differences in inhibitory control and children's theory of mind. Child Development, 72, 1032-1053.

Carlson, S. M., Moses, L. J., \& Claxton, L. J. (2004). Individual differences in executive functioning and theory of mind: An investigation of inhibitory control and planning ability. Journal of Experimental Child Psychology, 87, 299-319.

Cole, P. M., Martin, S. E., \& Dennis, T. A. (2004). Emotion regulation as a scientific construct: Methodological challenges and directions for child development research. Child Development, 75, 317-333.

Davidson, R. J., Pizzagalli, D., Nitschke, J. B., \& Kalin, N. H. (2003). Overview of circuitry underlying emotion and emotion regulation: Comparing the emotional brains of humans and other animals. In K. Scherer \& R. Davidson (Eds.), Handbook of affective sciences, Part I: Neuroscience. Oxford: Oxford University Press.

Davidson, R. J., Putnam, K. M., \& Larson, C. L. (2000). Dysfunction in the neural circuitry of emotion regulation: A possible prelude to violence. Science, 289, 591-594.

Davis, E. P., Bruce, J., \& Gunnar, M. R. (2002). The anterior attention network: Associations with temperament and neuroendocrine activity in 6-year-old children. Developmental Psychobiology, 40, 43-65.

Denham, S. A. (1986). Social cognition, prosocial behavior, and emotion in preschoolers: Contextual validation. Child Development, 57, 194-201.

Denham, S. A. (1998). Emotional development of young children. New York: Guilford.

Denham, S. A. (2006). Social-emotional competence as support for school readiness: What is it and how do we assess it? Early Education and Development, 17, 57-89.

Denham, S. A., Blair, K. A., DeMulder, E., Levitas, J., Sawyer, K. S., AuerbachMajor, S. T., et al. (2003). Preschool emotional competence: Pathway to social competence. Child Development, 74, 238-256. 
Denham, S. A., Zoller, D., \& Couchoud, E. (1994). Socialization of preschoolers' emotion understanding. Developmental Psychology, 30, 928-936.

Eisenberg, N., Fabes, R. A., Guthrie, I. K., Murphy, B. C., Maszk, P., Holmgren, R., et al. (1996). The relations of regulation and emotionality to problem behavior in elementary school children. Development and Psychopathology, 8, 141-162.

Eisenberg, N., Fabes, R. A., Murphy, B., Maszk, P., Smith, M., \& Karbon, M. (1995). The role of emotionality and regulation in children's social functioning: A longitudinal study. Child Development, 66, 1360-1384.

Espy, K., McDiarmid, M., Cwik, M., Stalets, M., Hamby, A., \& Senn, T. (2004). The contribution of executive functions to emergent mathematic skills in preschool children. Developmental Neuropsychology, 26, 465-486.

Flavell, J. H., Flavell, E. R., \& Green, F. L. (1983). Development of the appearancereality distinction. Cognitive Psychology, 15, 95-120.

Flavell, J. H., Miller, P. H., \& Miller, S. A. (2002). Cognitive development (4th ed.). Upper Saddle River, NJ: Prentice Hall.

Gaskins, I. W. (1994). Classroom applications of cognitive science: Teaching poor readers how to learn, think, and problem solve. In K. McGilly (Ed.), Classroom lessons: Integrating cognitive theory and classroom practice (pp. 129-154). Cambridge, MA: MIT Press.

Gathercole, S., Brown, L., \& Pickering, S. (2003). Working memory assessments at school entry as longitudinal predictors of National Curriculum attainment levels. Educational and Child Psychology, 20, 109-122.

Gerstadt, C. L., Hong, Y. J., \& Diamond, A. (1994). The relation between cognition and action: Performance of children $3 \frac{1}{2}-7$ years old on a Stroop-like daynight test. Cognition, 53, 129-153.

Gray, J. R. (2004). Integration of emotion and cognitive control. Current Directions in Psychological Science, 13, 46-48.

Griffin, S. A., Case, R., \& Siegler, R. S. (1994). Rightstart: Providing the central conceptual prerequisites for first formal learning of arithmetic to students at risk for school failure. In K. McGilly (Ed.), Classroom lessons: Integrating cognitive theory and classroom practice (pp. 25-49). Cambridge, MA: MIT Press.

Halberstadt, A. G., Denham, S. A., Dunsmore, J. C. (2001). Affective social competence. Social Development, 10, 79-119.

Hughes, C., \& Ensor, R. (2005). Executive function and theory of mind in 2 year olds: A family affair? Developmental Neuropsychology, 28(2), 645-668.

Kaufman, A. S., \& Kaufman, N. L. (1983). Kaufman Assessment Battery for Children $(K-A B C)$. Circle Pines, MN: American Guidance Service.

Kline, R. B. (1998). Principles and practice of structural equation modeling (pp. 211-216). New York: Guilford. 
Kopp, C. B. (1989). Regulation of distress and negative emotions: A developmental view. Developmental Psychology, 25, 343-354.

Lewis, M. D., \& Stieban, J. (2004). Emotion regulation in the brain: Conceptual issues and directions for developmental research. Child Development, 75, 371-376.

Nigg, J. T., \& Huang-Pollock, C. L. (2003). An early-onset model of the role of executive functions and intelligence in conduct disorders/delinquency. In B. Lahey, T. Moffitt, \& A. Caspi (Eds.), Causes of conduct disorder and juvenile delinquency (pp. 227-253). New York: Guilford.

Perner, J., Lang, B., \& Kloo, D. (2002). Theory of mind and self-control: More than a common problem of inhibition. Child Development, 73, 752-767.

Posner, M. I., \& Rothbart, M. K. (2000). Developing methods of self-regulation. Development and Psychopathology, 12, 427-441.

Pressley, M. (1995). What is intellectual development about in the 1990s? Good information processing. In F. E. Weinert \& W. Schneider (Eds.), Memory performance and competencies: Issues in growth and development (pp. 375-404). Hillsdale, NJ: Erlbaum.

Putnam, S. P., \& Rothbart, M. K. (2003). Development of short and very short forms of the Children's Behavior Questionnaire. Unpublished manuscript.

Riggs, N. R., Blair, C. B., \& Greenberg, M. T. (2003). Concurrent and 2-year longitudinal relations between executive function and the behavior of 1 st and 2 nd grade children. Child Neuropsychology, 9, 267-276.

Saarni, C. (1990). Emotional competence. In R. A. Thompson (Ed.), Nebraska Symposium: Socioemotional development (pp. 115-161). Lincoln: University of Nebraska Press.

Schultz, D., Izard, C. E., Ackerman, B. P., \& Youngstrom, E. A. (2001). Emotion knowledge in economically disadvantaged children: Self-regulatory antecedents and relations to social difficulties and withdrawal. Development and Psychopathology, 13, 53-67.

Shields, A., \& Cicchetti, D. (1998). Reactive aggression among maltreated children: The contributions of attention and emotion dysregulation. Journal of Child Clinical Psychology, 27, 381-395.

Stein, N. L., \& Jewett, J. L. (1986). A conceptual analysis of the meaning of negative emotions: Implications for a theory of development. In C. E. Izard \& P. B. Read (Eds.), Measuring emotions in infants and children: Vol. 2. Cambridge Studies in Social and Emotional Development (pp. 238-267). New York: Cambridge University Press.

Stipek, D. J., \& Ryan, R. H. (1997). Economically disadvantaged preschoolers: Ready to learn but further to go. Developmental Psychology, 33, 711-723.

Stroop, J. R. (1935). Studies of interference in serial verbal reactions. Journal of Experimental Psychology, 18, 643-662. 
Tager-Flusberg, H., \& Sullivan, K. (2000). A componential view of theory of mind: Evidence from Williams syndrome. Cognition, 76, 59-89.

Walden, T. A., \& Field, T. M. (1990). Preschool children's social competence and production and discrimination of affective expressions. British Journal of Developmental Psychology, 8, 65-76.

Walden, T. A., \& Smith, M. (1997). Emotional regulation. Motivation and Emotion, $21,7-25$.

Watson, A. C., Nixon, C. L., Wilson, W., \& Capage, L. (1999). Social interaction skills and theory of mind in young children. Developmental Psychology, 35, 386-391.

Woodcock, R. W., McGrew, K. S., \& Mather, N. (2001). Woodcock-Johnson III $A C H$. Itasca, IL: Riverside Publishing. 
Reproduced with permission of the copyright owner. Further reproduction prohibited without permission. 